\title{
Patient and Provider Perspectives of Disrespect and Abuse during Childbirth in Tanzania: A Literature Review
}

\section{Gopika Das ${ }^{1}$, Theresia John Masoi ${ }^{2}$, Stephen M. Kibusi ${ }^{2}$, Arun Chaudhary ${ }^{1,3}$, Mary Greenwald ${ }^{1}$, Annekathryn Goodman ${ }^{1 *}$}

${ }^{1}$ Department of Obstetrics and Gynecology, Strength and Serenity Global Initiative to End Gender-Based Violence, Massachusetts General Hospital, Boston, USA

${ }^{2}$ Department of Clinical Nursing, School of Nursing and Public Health, The University of Dodoma, Dodoma, Tanzania

${ }^{3}$ Abiral Foundation, Center for Sustainable Development Research, Kathmandu, Nepal

Email: ^agoodman@mgh.harvard.edu

How to cite this paper: Das, G., Masoi, T.J., Kibusi, S.M., Chaudhary, A., Greenwald, M. and Goodman, A. (2021) Patient and Provider Perspectives of Disrespect and Abuse during Childbirth in Tanzania: A Literature Review. Open Journal of $\mathrm{Ob}$ stetrics and Gynecology, 11, 1248-1272. https://doi.org/10.4236/ojog.2021.119118

Received: September 6, 2021

Accepted: September 26, 2021

Published: September 29, 2021

Copyright $\odot 2021$ by author(s) and Scientific Research Publishing Inc. This work is licensed under the Creative Commons Attribution International License (CC BY 4.0).

http://creativecommons.org/licenses/by/4.0/

\begin{abstract}
Objective: Disrespectful and abusive (D\&A) maternity care is a deterrent to facility childbirth and can thus contribute to child and maternal mortality. This study will review existing literature on D\&A in Tanzania to better understand and contextualize the issue. Methods: A comprehensive literature search was conducted to find relevant publications on D\&A during childbirth in Tanzania. The search was conducted on the National Center for Biotechnology Information (NCBI) and PubMed (U.S. National Library of Medicine at the National Institutes of Health). The inclusion criteria were as follows: qualitative, quantitative, and ethnographic studies conducted in Tanzania on obstetrical violence; published in English; focused on prevalence, incidence, root causes, historical trends, interventions, and policy recommendations for obstetrical violence in Tanzania. Results: Twenty-one studies were selected for this literature review. Up to $73.1 \%$ of women reported experiencing at least one form of D\&A during labor. Commonly reported D\&A events include non-dignified care, non-confidential care, and physical abuse. Other forms of D\&A, including detention in facilities and asking for unofficial payments, are also reported. Ninety-six percent of nurses, midwives, and nursing assistants in Tanzania self-reported engaging in at least one form of D\&A. Lack of training and provider support, long work hours, fear of blame, and limited infrastructure were reported as factors leading to D\&A by providers. Conclusions: In Tanzania, D\&A during childbirth is prevalent in healthcare systems. The direct relationship between D\&A and poor maternal and fetal health is well-documented. Individual and systemic factors influence
\end{abstract}


both provider and patient perspectives of D\&A, providing a window into a complex and sensitive phenomenon. It is important that D\&A in Tanzania be viewed holistically, and that interventions target the multifaceted nature of the issue.

\section{Keywords}

Disrespect and Abuse, Traumatic Birth, Traumatic Childbirth, Obstetrical Violence Dehumanized Birth, Tanzania

\section{Background}

\subsection{Introduction}

Dying in childbirth continues to be a major cause of mortality for women worldwide [1]. The leading direct causes of maternal death are mostly preventable and include hemorrhage, infections, unsafe abortions, hypertensive disorders, and obstructed labors. Maternal deaths in Tanzania (524 deaths per 100,000 live births) represent $18 \%$ of all deaths of women aged 15 - 49 years [2]. In Tanzania, as in other parts of the world, one major risk factor for dying is delivering a baby without medical and emergency backup [3]. Factors associated with delivering at home and using unskilled birth assistance in Tanzania are education level, marital status, number of antenatal visits, and walking distance to a health facility [4]. An additional factor both in Tanzania and in other countries is the reluctance to come to a birthing facility because of personal and community experiences with disrespect and abuse (D\&A) or obstetric violence [5].

The conversation around respectful maternity care began in the early 1990s with the passage of the United Nations "Declaration on the Elimination of Violence against Women" [6]. The declaration urged immediate action against the sexual, physical, and psychological suffering and harm caused to victims. It paved the way for women's rights advocacy in every sphere of life. Simultaneously, a powerful movement calling for the "humanization" of childbirth gained footing in Latin America [7]. The movement advocated for increased respect for and promotion of women's right to access health assistance based on scientific evidence and efficacy rather than on the convenience of healthcare systems. With the adoption of the United Nations Millennium Development Goals around the same time, the reduction of maternal mortality and morbidity became a global priority [8]. Facility births under the supervision of skilled providers were increasingly encouraged, especially in low-income countries. However, a crucial question had to be answered first: why do women not deliver at facilities?

While access to skilled and appropriate maternal healthcare has increased in recent years, and facility births are encouraged, there remains a gap in facility utilization, especially in resource-limited countries. Maternal health experts 
contend that disrespectful and abusive events experienced by birthing mothers pose a significant barrier to optimal use of maternity care [9]. Disrespect and abuse (D\&A) is defined as the interactions, facility conditions, and experiences that are intended to be or are deemed to be humiliating or undignified as established by local consensus. D\&A may also be referred to as mistreatment, obstetric violence, or dehumanized care [10].

In 2010, the United States Agency for International Development (USAID) commissioned a landscape analysis on disrespect and abuse during facility-based childbirth [10]. The analysis, conducted by Diane Bowser and Kathleen Hill, has since served as a framework for categorizing and describing disrespectful behavior of providers of obstetrical care. Bowser and Hill identified seven broad categories of D\&A during childbirth: physical abuse, non-consented care, nonconfidential care, discrimination based on specific patient attributes, non-dignified care, abandonment of care, and detention in facilities pending payment [10]. These categories act as umbrella terms for a variety of D\&A events and are based squarely on foundational principles of bioethics (Table 1). It is important to note that the seven categories are not mutually exclusive.

Disrespectful and abusive maternity care is a global phenomenon which has garnered increased attention in recent years. Several studies have been conducted to establish the prevalence of D\&A events in different regions. In the

Table 1. D\&A categories described by Bowser and Hill [10].

\begin{tabular}{|c|c|}
\hline D\&A Category & Manifestation \\
\hline Physical abuse & $\begin{array}{l}\text { Beatings, slapping, pinching, forcefully pushing } \\
\text { on abdomen, sexual abuse }\end{array}$ \\
\hline Non-consented care & 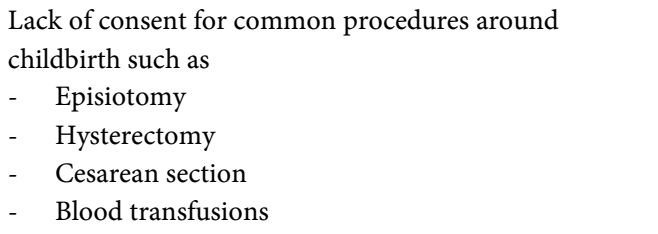 \\
\hline Non-dignified care & $\begin{array}{l}\text { Intentional humiliation, blaming, scolding, public } \\
\text { disclosure of private health information, rough handling }\end{array}$ \\
\hline Non-confidential care & $\begin{array}{l}\text { Lack of physical privacy } \\
\text { Lack of privacy related to sensitive health information }\end{array}$ \\
\hline Abandonment of care & $\begin{array}{l}\text { Patient ignored when asking for help, patient gives } \\
\text { birth without attention }\end{array}$ \\
\hline $\begin{array}{l}\text { Discrimination based on } \\
\text { specific attributes }\end{array}$ & 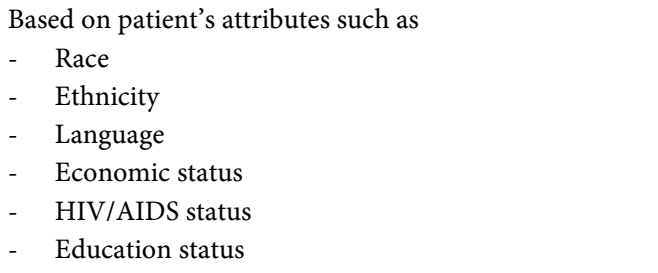 \\
\hline $\begin{array}{l}\text { Detention in facility pending } \\
\text { payment }\end{array}$ & Inappropriate demands for payment \\
\hline
\end{tabular}


African continent, estimates vary from $73 \%$ of women reporting at least one D\&A experience in Tanzania to $98 \%$ of women in Nigeria [11]. Most frequently reported D\&A events include non-confidential care and non-dignified care, followed by physical abuse.

Disrespectful and abusive maternity care is a deterrent to facility childbirth and can thus contribute to maternal mortality. This study will review the existing literature on D\&A in Tanzania to better understand and contextualize the issue in this country. In addition, cultural, tribal, and regional mores of pregnancy, childbirth, and women's autonomy which influence medical decisions will be reviewed to better understand the local context of D\&A as well as the baseline supports and challenges experienced by women in Tanzania. This knowledge can be harnessed to strengthen health policy, monitor obstetric D\&A events, develop maternal health educational programs for health workers and add to recommendations on improving respectful and woman friendly facility infrastructure.

This introduction includes a country overview, a summary of reproductive and neonatal health indicators, and a review of birthing traditions and cultural beliefs in Tanzania.

\subsection{Country Overview}

The Republic of Tanzania is the largest country in East Africa, covering 940,000 square kilometers and sharing borders with eight other countries [12]. Tanzania has a population of approximately 59 million people [13]. There are 129 different ethnic groups in the country with four major African language bases, including Bantu, Cushitic, Nilotic, and Khoisan [14]. While each ethnic group boasts its own culture, language, and social organization, they are similar in their customs and traditions as well as having Swahili as the national language. Despite the ethnic diversity of its population, Tanzania has historically enjoyed peace and stability [15]. Tanzania has a mixed economy with the service industry constituting 52\% of the gross domestic product (GDP) [12]. The agriculture sector, comprising crops, fishery, forestry, hunting, and animal husbandry, plays a key role in the economy.

During the last decade, the Tanzanian government has enacted legal and public policy interventions aimed at increasing women's empowerment, contributing to an upward trend in education, financial autonomy, and the overall well-being of Tanzanian women. In 2015, just under $25 \%$ of females six years and older had no formal education, compared with $19 \%$ of males [12]. Once boys and girls enter school, their completion rates are similar. A 2015-2016 study by Demographic and Health Survey (DHS) indicates that more than eight out of ten married women are employed in Tanzania; however, approximately $42 \%$ of employed married women are not paid for their work [12]. The corresponding proportion for employed married men is significantly lower at only $10 \%$. Most women do not have financial autonomy and make joint decisions 
with their spouses on how to spend their earnings. They lack autonomy in decisions regarding healthcare, family visits, and major household purchases too. Only thirty-five percent of married women participate in all three decisions, which is an increase from 25\% participation reported in the 2004-2005 Tanzania DHS survey [12].

Female genital circumcision (FGC) can be considered a marker for the violation of a woman's human rights and carries the significant health consequences of infections, obstetrical complications, and psychological distress [16]. FGC is prevalent across Tanzania and has been a historic cultural tradition, though rates have declined over the past few decades. One in ten Tanzanian women have been circumcised, and its prevalence is larger in older women. 19\% of women between the ages of 45 - 49 years have been circumcised, compared to $5 \%$ of women aged 15 - 19 years [12]. Over $80 \%$ of female circumcisions in Tanzania involve the cutting and removal of genital flesh [12]. Increased awareness of the harms of FGC is changing public attitudes. The 2015-2016 Tanzania DHS survey found that $95 \%$ of women do not believe in the practice and do not think it should continue [12].

\subsection{Maternal and Newborn Health Indicators}

Tanzania has experienced a steady decline in birth rates over the last two decades, with rates varying across regions, education levels, and economic status. According to the 2015-2016 DHS report, Tanzanian women on average have 5.2 children [12]. The number of children is lower in urban mainland areas, where a larger proportion of women have attained secondary level education and/or increased household wealth.

Table 2 summarizes recent maternal and neonatal health indicators in Tanzania. The maternal mortality ratio (MMR) is defined as the number of maternal deaths per 100,000 live births during a given time-period. Specifically, MMR reports the death of a woman while pregnant or within 42 days of termination of pregnancy, irrespective of the duration and site of pregnancy (uterine or extrauterine) from any cause related to or made worse by pregnancy or its management. It serves as an indicator of the risk of maternal death during a single live birth [17]. Recent estimates from the 2017 World Bank report on Tanzania

Table 2. 2017 maternal and neonatal health indicators in Tanzania*.

\begin{tabular}{cc}
\hline Indicator & Population Data \\
\hline Maternal Mortality Ratio (MMR) & 578 \\
Lifetime Risk of Maternal Death & $3 \%$ \\
Average Number of Children & 5.2 \\
Infant Mortality Rate & $4.3 \%$ \\
Preterm Birth Rate & $11 \%$ \\
Number of Premature Births & 236,000 \\
\hline
\end{tabular}

${ }^{\star}$ World Bank Report [18]. 
indicate an MMR of 578 deaths per 100,000 live births [2]. Additionally, the lifetime risk of maternal death, which refers to the probability that a 15 -year-old woman will eventually die from a maternal cause, is 0.030 in Tanzania [18]. This indicates that $3 \%$ of Tanzanian women will die during pregnancy, childbirth, or within two months of delivery over their lifetime.

The infant mortality rate is an estimate of the risk of dying within one year of birth and is represented as the number of deaths per 1000 live births [19]. The infant mortality rate in Tanzania has decreased from 90 deaths per 1000 live births in 1991 to 43 deaths per 1000 live births in 2015 [12]. Contrary to expectations, the 2015-2016 TDHS found an increase in infant deaths in urban areas and higher wealth households. The cause of this unexpected finding is unknown and requires further investigation.

The preterm birth rate is defined as the probability of a baby being born alive before 37 completed weeks of pregnancy, per 100 live births. The preterm birth rate in Tanzania is $11 \%$, which translates into 236,000 babies born prematurely per year [20]. These indicators are crucial in highlighting gaps in health systems in Tanzania requiring urgent attention.

\subsection{Birthing Traditions}

Antenatal care visits (ANC) are integral to good maternity care. The visits allow healthcare providers to examine and screen women for serious health concerns, as well as to disseminate crucial information regarding pregnancy, childbirth, and the postpartum period. The World Health Organization (WHO) recommends that ANC be sought early, with the first visit occurring during the first trimester of pregnancy [21]. Early ANC visits allow for identification of the risk of pre-eclampsia and other life-threatening complications, which left untreated can lead to poor maternal and fetal outcomes. Moreover, studies show a positive correlation between completion of the recommended number of ANC visits and delivery in a health facility under the care of a skilled professional [21].

There is a high uptake of ANC in Tanzania, where these medical services are mostly free. In 2015, 98\% of women between the ages of 15 - 49 years had received antenatal care during their most recent pregnancy [12]. Per international guidelines, the Tanzanian Ministry of Health recommends a minimum of four antenatal visits during pregnancy [22]. The current recommended ANC guidelines as per the Tanzania Ministry of Health in 2018, in line with WHO guidelines, recommend a minimum of eight ANC contacts starting from up to twelve weeks of pregnancy, then at 20,26,30,34,36,38, and 40 weeks. This new model of increased ANC contacts is associated with a more positive pregnancy experience.

In $2015,51 \%$ of all women had at least four antenatal care visits during their last pregnancy. However, records indicate that only $24 \%$ of women started ANC visits within the recommended time frame [12]. Distance, lack of transportation, and lack of decision-making power are among the most common reasons that prevent women from attending the optimal number of ANC visits [22]. Given 
the impact of antenatal care on maternal and fetal health outcomes, it is crucial to understand the barriers to the uptake of comprehensive universal ANC in Tanzania.

As shown in Figure 1, over the last two decades, Tanzania has seen an increase in the number of births occurring in health facilities (defined in this review as a hospital or birthing center where a woman delivers under the care of doctors, midwives, or nurses). Figure 1 summarizes these trends. The proportion of births occurring in health facilities increased from 47\% in 2004 to $63 \%$ in 2015 [12]. Similarly, there has been an increase in the number of births assisted by skilled providers in Tanzania. Over $64 \%$ of births were attended by a provider in 2015 [12]. Given the upward trend in provider-assisted births, it is crucial to understand providers' perspectives on D\&A and leverage their expertise to improve maternal and fetal health outcomes in Tanzania.

Maternity care is provided along a continuum of healthcare facilities in Tanzania. Dispensaries function at the primary level, followed by health centers and district hospitals at the next tier [23]. Each facility is required to provide basic emergency obstetric care (EmOC) and routine maternity care. At the district hospitals, more comprehensive EmOC services are available, including cesarean sections and blood transfusions [23]. Most facility births occur in public healthcare centers. Mothers living in urban areas, with secondary or more education and/or from wealthy households are more likely to give birth in facilities. In $2015,36 \%$ of births occurred at home [12]. It is important to note, however, that these numbers may be an underestimate. Practices during past pregnancies are strongly associated with decisions about the birth locale. The mother is more likely to give birth at home if she or other family members have had successful deliveries at home in the past. Male partner's involvement in maternity care has been more acceptable to older and more educated patients and this is an area

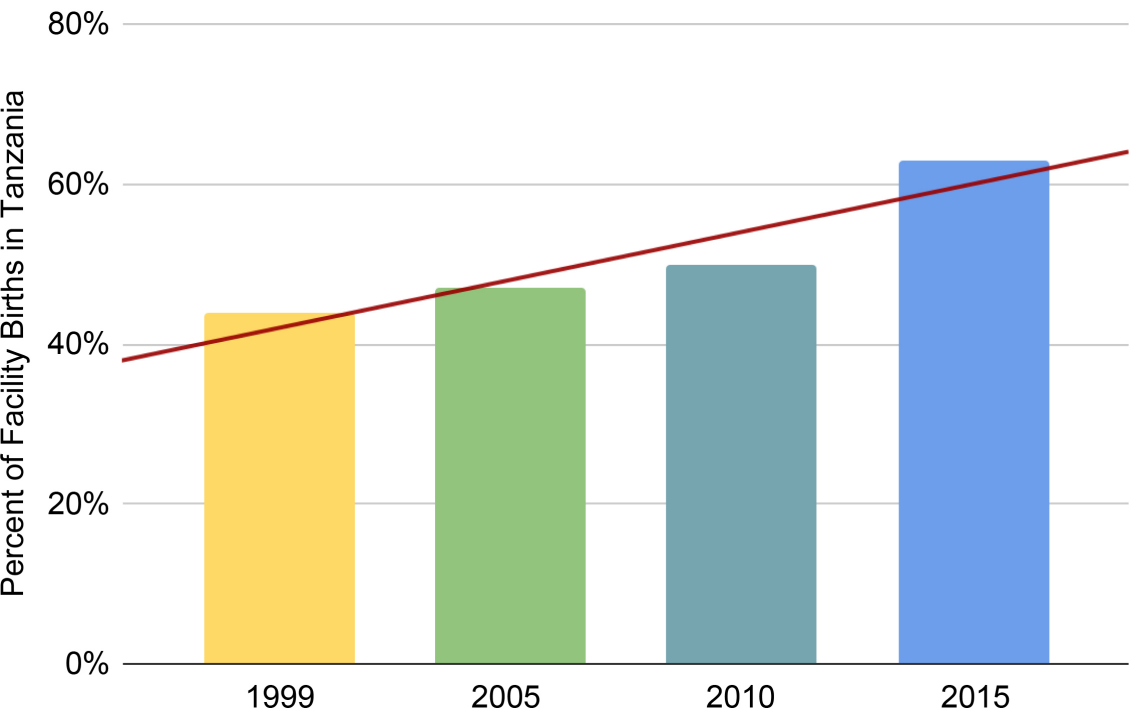

Figure 1. Percent of Facility* Births in Tanzania 1999-2015. Source: Tanzania DHS 2015-2016 [12]. *Facility births include hospitals and birthing centers. 
where more education and outreach to younger women can increase attendance at health facilities [24].

While not normative (see Figure 1), in a study conducted in the northwestern part of Tanzania, women who began labor at home were moved to a health facility before delivery as a method to reduce obstetric fistula [22]. Once in labor, the decision-making power typically lies with the woman's in-laws and parents, which may explain the transfer to a facility at that juncture. In a minority of cases, the transfer was recommended by a traditional birth attendant (TBA).

\subsection{Cultural Beliefs}

In Tanzania, socio-cultural norms and traditions play a significant role in determining the location of birth. The decision is commonly made by the husband and/or mother-in-law with little to no participation from the pregnant woman [25]. In many regions of the country, women who deliver at home are regarded by their families and society as "healthy" and their pregnancies and childbirth are considered low risk [26]. Home deliveries are attended by traditional birth attendants (TBAs), and other female members of the family.

Men typically have limited decision-making power in the process of birth; their role is to provide financial and material support [26]. Many women prefer to deliver at home to be able to partake in traditional rituals that accompany childbirth in Tanzania. For example, killing and serving goat meat and local beer to relatives and friends is a common childbirth ritual in the Kilimanjaro region of the country [25]. Additionally, there are social norms around privacy during childbirth which are difficult to uphold in health facilities. Birth is widely regarded as a private event that is not to be shared with those from outside the family. Similarly, communities in the Kilimanjaro region believe that to ward off evil, no one outside the family should see the baby until the umbilical cord has fallen off [25]. With limited resources and space capacity at dispensaries, health centers, and district hospitals, privacy may be elusive, particularly in Tanzania's public health facilities. There are a lot of undocumented practices across all the tribes apart from Kilimanjaro, regarding childbirth including handling of stillbirth, death of a woman during birth and having a breech delivery as well as having twins.

\section{Methods}

A comprehensive literature search was conducted to find relevant publications on D\&A during childbirth in Tanzania. The search was conducted on the National Center for Biotechnology Information (NCBI) and PubMed (U.S. National Library of Medicine at the National Institutes of Health). The keywords used in the search included "disrespect and abuse", "traumatic birth", traumatic childbirth", "obstetrical violence", and "dehumanized birth".

Inclusion and exclusion criteria were applied to the abstracts of the resulting publications. Selected literature was then reviewed in its entirety for suitability. 
The inclusion criteria were as follows: qualitative, quantitative, and ethnographic studies conducted in Tanzania on obstetrical violence; published in English; focused on prevalence, incidence, root causes, historical trends, interventions, and policy recommendations for obstetrical violence in Tanzania. No time-period limit was applied. Studies were excluded if they were conducted outside Tanzania, focused on the impact of rape, sexual violence, or intimate partner violence on childbirth and maternal health, or examined the efficacy of clinical care practices rather than the quality of care. Additionally, multi-country studies in which distinct data for Tanzania could not be extracted were excluded. A total of 21 studies were included in the literature review. Figure 2 summarizes the Prisma diagram for this review.

\section{Results}

\subsection{Methodology of Reviewed Studies}

Twenty-one studies were selected for this literature review. Seven studies focused on the healthcare provider's perspective of D\&A in Tanzania [23] [27]-[32]. Fourteen studies centered around the patient's perspectives [9] [29] [33]-[38]. The studies represent a range of methodologies: three naturalistic

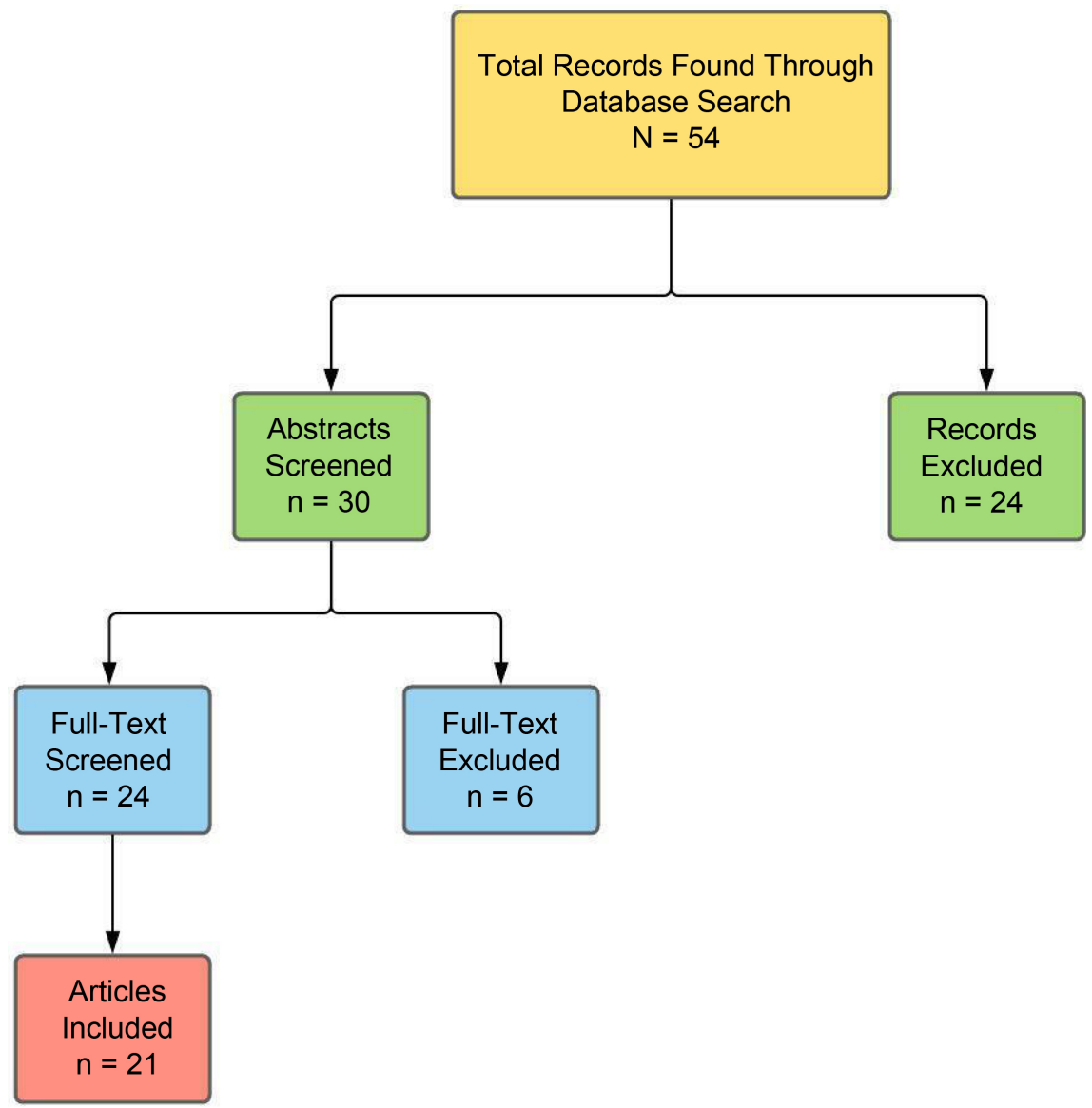

Figure 2. Prisma diagram for comprehensive literature search on disrespect and abuse during childbirth in Tanzania. 
observational studies of healthcare providers; four semi-structured qualitative interviews of healthcare providers; ten mixed-method studies administered in the postpartum, including two follow-up interviews at greater than four weeks postpartum; and four reviews of existing literature, policies, and interventions. Table 3 describes the specifics of the methodologies used in these studies.

The selected studies provide a window into the D\&A landscape in Tanzania. Prevalence estimates vary significantly across patient experiences, provider perspectives, and research observations. Patient experiences and reports of D\&A are unarguably the most important tool to understand this phenomenon. Table 4 highlights the selected literature on the patient's perspectives in Tanzania. In a study conducted in the Mara and Kagera region of Tanzania, 73.1\% of women reported experiencing at least one form of D\&A during labor [33]. Similarly, in the Tanga region, one in five women reported experiencing D\&A during facility childbirth [34]. The prevalence is similar in urban areas, with $15 \%$ of women reporting at least one form of D\&A in a large referral hospital in Dar es Salaam [35]. Many researchers have adopted the Bowser and Hill D\&A categorization and adapted it to the Tanzanian context. Commonly reported D\&A events include non-dignified care, non-confidential care, and physical abuse [27]. Other forms of D\&A, including detention in facilities and asking for unofficial payments, are also reported [34]. Multiple women across studies reported a lack of supportive companions during the labor process [36]. Some women have also voiced the need for a more comforting and less daunting healthcare environment.

\subsection{Patient Perspective}

Patient self-reporting may be influenced by interview or survey timing. As highlighted in Table 4, typically, there is an increase in D\&A reporting after several weeks postpartum compared to the time of discharge. In the exit survey, only $19.48 \%$ of women reported experiencing at least one form of D\&A, but $28.21 \%$

Table 3. Description of selected study methodologies.

\begin{tabular}{ll}
\hline \multicolumn{1}{c}{ Methodology } & \multicolumn{1}{c}{ Description } \\
\hline Naturalistic Observation Study & $\begin{array}{l}\text { A type of field research method which involves } \\
\text { observing the participant's behaviors in the } \\
\text { environment in which it typically occurs [39] }\end{array}$ \\
& $\begin{array}{l}\text { Participants are required to answer preset } \\
\text { open-ended questions during an in-depth } \\
\text { interview. The questions are based on a } \\
\text { preset interview guide [40] }\end{array}$ \\
Mixed-Methods Study & $\begin{array}{l}\text { Quantitative and qualitative data is collected and } \\
\text { analyzed within the same research study [41] }\end{array}$ \\
Comprehensive review of all prior literature on the \\
Literature Reviews
\end{tabular}


Table 4. Patient perspective of D\&A in Tanzania.

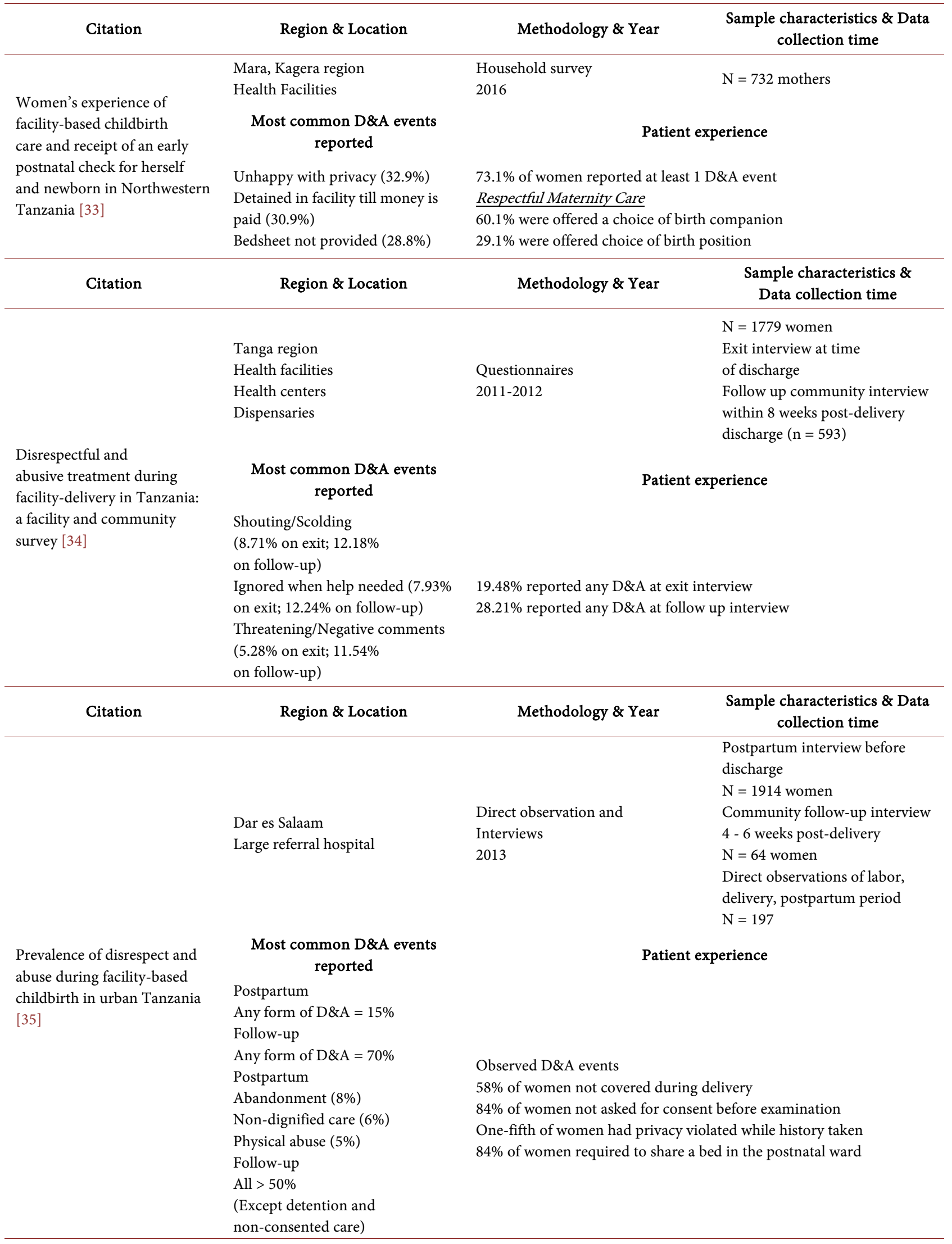




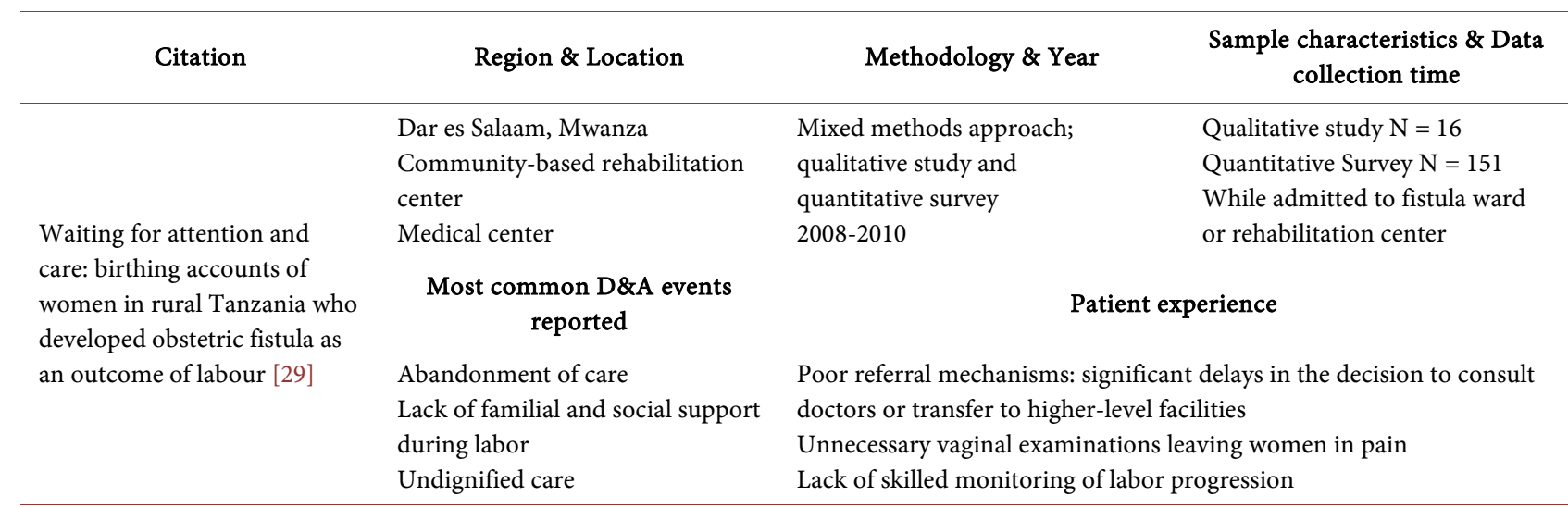

\section{Citation}

Region \& Location
Methodology \& Year

Qualitative descriptive

study design

\section{Sample characteristics \& Data collection time}

\begin{abstract}
Mwanza and Mara region
Regional referral hospitals
\end{abstract}

Humanizing birth in Tanzania: a qualitative study on the (mis) treatment of women during childbirth from the perspective of mothers and fathers [36]

\section{Most common D\&A events reported}

Verbal abuse

Failure to meet professional standards of care

Poor rapport between mother and providers
Semi-structured Interviews

$\mathrm{N}=12$

Focus group discussions

$\mathrm{N}=4$

During postnatal clinic visit

\section{Patient experience}

Experienced harsh and rude language from providers which discouraged help-seeking behaviors during labor Unconsented surgical operations, lack of anesthesia for pain management during stitching, neglect, and abandonment of care Poor communication, lack of provider support, absence of companion during birth

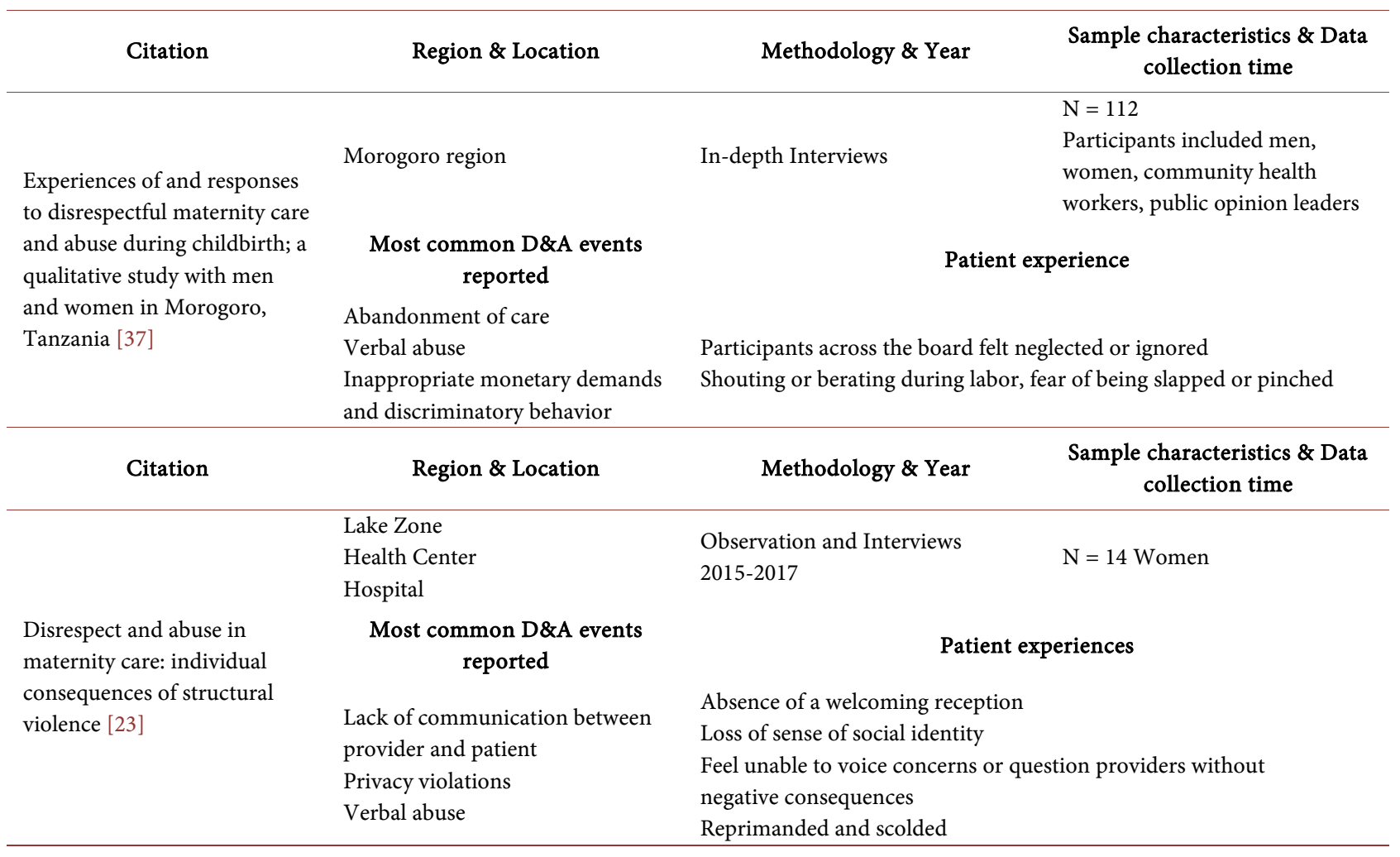




\begin{tabular}{|c|c|c|c|}
\hline Citation & Region \& Location & Methodology \& Year & $\begin{array}{c}\text { Sample characteristics \& Data } \\
\text { collection time }\end{array}$ \\
\hline \multirow[b]{2}{*}{$\begin{array}{l}\text { Eye of the beholder: } \\
\text { observation vs self-report in } \\
\text { the measurement of D\&A } \\
\text { during facility-based birth } \\
\text { [43] }\end{array}$} & $\begin{array}{l}\text { Tanga region } \\
\text { Hospitals }\end{array}$ & $\begin{array}{l}\text { Observation and Exit } \\
\text { questionnaires } \\
2012,2015\end{array}$ & $\begin{array}{l}\text { Baseline } \mathrm{N}=232 \text { women } \\
\text { End line } \mathrm{N}=237 \text { women }\end{array}$ \\
\hline & $\begin{array}{l}\quad \begin{array}{c}\text { Most common D\&A events } \\
\text { reported }\end{array} \\
\text { Prevalence by observer }> \\
\text { prevalence reported } \\
\text { Baseline any D\&A } \\
\text { Observation }=69.83 \% \\
\text { Self-report }=9.91 \% \\
\text { End line } \\
\text { Observation }=32.91 \% \\
\text { Self-report }=7.59 \%\end{array}$ & $\begin{array}{l}\text { Privacy violations not limited } \\
\text { Non-clinical personnel presen } \\
\text { Threatening to withhold treat } \\
\text { behavior during labor } \\
\text { Ignoring care-seeking behavio }\end{array}$ & $\begin{array}{l}\text { structural restrictions. } \\
\text { ical areas. } \\
\text { r non-compliant }\end{array}$ \\
\hline
\end{tabular}

reported D\&A in the follow-up survey five to ten weeks postpartum [34]. Similarly in another study, only $15 \%$ of participants reported experiencing any type of D\&A after birth prior to being discharged, while at four to six weeks postpartum that prevalence increased to $70 \%$ [35]. This distinct difference in prevalence estimates following passage of time requires a deeper analysis of potential reporting biases. Figure 3 summarizes the differences in patient-identified D\&A.

\subsection{Provider Perspective}

There is an increasing body of literature on provider's perspectives of D\&A behaviors. Table 5 presents the chosen literature on the provider's perspective in Tanzania. Researchers have asked healthcare providers to reflect on and self-report their D\&A behaviors. According to a study of 439 nurses, midwives, and nursing assistants in Tanzania, 96.1\% of participants self-reported engaging in at least one form of D\&A [27]. It is important to analyze the influence of infrastructural restrictions and socio-cultural determinants on provider behaviors. One of the most frequently reported D\&A events across studies is the lack of confidential care or privacy, particularly during vaginal examinations. A study conducted in Tanzania indicated that over $90 \%$ of postpartum women had to share their beds with others. As a result, privacy is scarce [35]. In addition to facility and infrastructure restrictions, individualized barriers to respectful maternity care also persist. Lack of familiarity with traditional herbal medicines and traditions leads providers to reject such alternatives in favor of westernized evidence-based medical care [29]. This disregard may contribute to the feelings of alienation and disrespect in mothers.

A Tanzanian observational study of fourteen midwives found each of them committed at least one form of D\&A [27]. Similarly, researchers observed that $84 \%$ of women experienced non-consented care, and $58 \%$ were not covered by a 
At Discharge $\square+$ + Weeks Postpartum

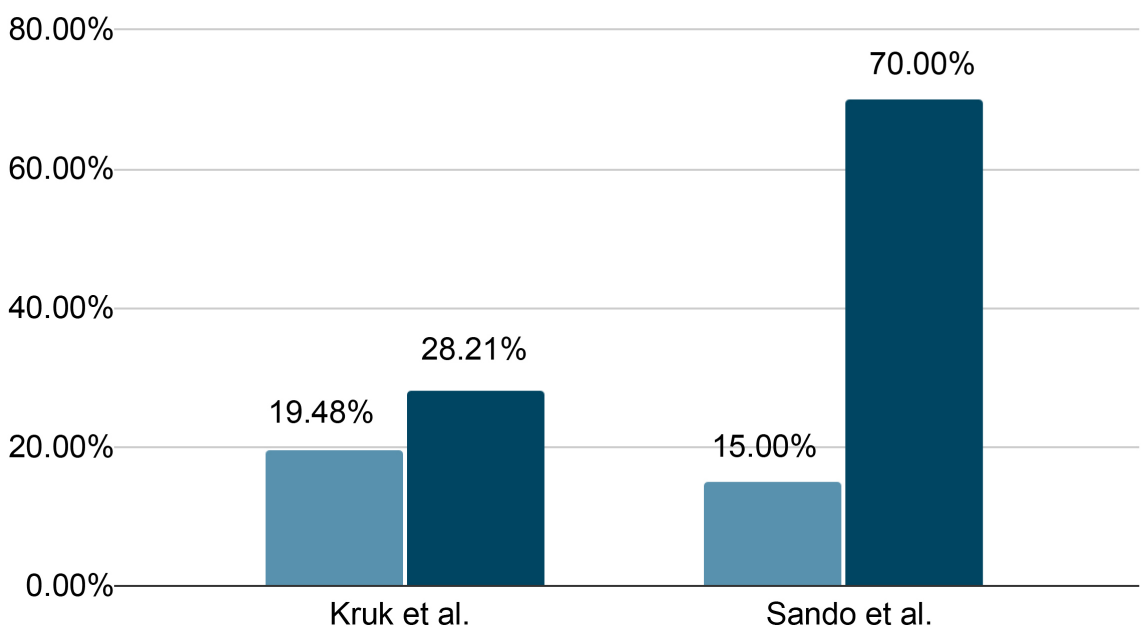

Figure 3. Patient reports of disrespect and abuse in childbirth at discharge vs. 4+ weeks postpartum.

sheet during delivery (non-confidential care) [28]. Observational studies have yielded insights into D\&A practices such as suturing of perineal tears without the use of anesthesia, administering the incorrect dosage of oxytocin to stimulate labor contractions, and rupturing membranes with fragments of broken glass ampules that may not typically be reported [28]. Psychological abuse and abandonment of care were also observed, with nurses and midwives failing to console or support women during delivery.

\subsection{Interventions for $\mathrm{D} \& \mathrm{~A}$}

Summarized in Table 6 is the Staha intervention, a Tanzanian participatory community and health system intervention on D\&A [44]. Implemented in two hospitals in the Tanga region, the intervention utilized a client service charter to improve the quality of maternity care. The focal point of the intervention was community and facility stakeholders acutely familiar with the situation. Post-intervention results indicated a 3.39\% decrease in women who experienced D\&A in the intervention sites, as well as the lowered likelihood of D\&A instances reported.

\section{Discussion}

Throughout Tanzania, D\&A in childbirth is prevalent in its healthcare system. While the prevalence varies, D\&A remains a significant concern. The literature analyzed in this paper highlights the evidence of the relationship between D\&A and poor maternal and fetal health is well-documented. The literature analyzed in this paper highlights these trends. Individual and systemic factors influence both provider and patient perspectives of $\mathrm{D} \& \mathrm{~A}$, providing a window into a complex and sensitive phenomenon. It is important that D\&A in Tanzania be viewed holistically, and that interventions target the multifaceted nature of the issue. 
Table 5. Provider perspective on D\&A in Tanzania.

\begin{tabular}{|c|c|c|c|c|}
\hline Citation & Region \& Location & Methodology \& Year & Sample characteristics & Researcher observations \\
\hline $\begin{array}{l}\text { Self-reported } \\
\text { disrespect and } \\
\text { abuse by nurses } \\
\text { and midwives [27] }\end{array}$ & $\begin{array}{l}\text { Dar es Salaam, Mbeya, } \\
\text { Mwanza; } \\
\text { Referral level hospitals; } \\
\text { Regional hospitals; } \\
\text { District hospitals; } \\
\text { Health centers. }\end{array}$ & $\begin{array}{l}\text { Questionnaires } \\
2016\end{array}$ & $\begin{array}{l}\mathrm{N}=439 \\
\text { Nurses, midwives, nursing } \\
\text { assistants }\end{array}$ & $\begin{array}{l}96.1 \% \text { reported enacting } \\
\text { one form of D\&A; } \\
25 \% \text { - } 44 \% \text { relating to } \\
\text { psychological abuse during } \\
\text { labor and childbirth; } \\
\text { D\&A events increased with } \\
\text { increase in working } \\
\text { hours/week and taking } \\
\text { break during evening shifts; } \\
\text { D\&A events decreased with } \\
\text { job satisfaction and } \\
\text { supervision of any form. }\end{array}$ \\
\hline
\end{tabular}

\begin{tabular}{llll}
\hline Citation & Region \& Location & Methodology \& Year & Sample characteristics \\
\hline & Mwanza, Mara & Semi-structured & $\mathrm{N}=8$ \\
District Hospitals & interviews & Midwives, obstetricians
\end{tabular}

Barriers and self-facilitators to humanizing birth care in Tanzania [29]
Provider explanation

Barriers to providing quality care

Systematic barriers

Limited physical space

Facility limitations

Individualized barriers

Limited birth position choice

Disrespect for beliefs of mother

\section{Recommendations}

Facilitators to RMC

Systematic facilitators

Education on RMC (ongoing)

Continuous clinic support during birth

Benefit of having family be active participants during birth

Respecting maternal wishes when appropriate/feasible

\begin{tabular}{|c|c|c|c|c|}
\hline Citation & Region \& Location & Methodology \& Year & Sample characteristics & Researcher observations \\
\hline $\begin{array}{l}\text { Midwives respect } \\
\text { and disrespect of } \\
\text { women during } \\
\text { facility-based } \\
\text { childbirth } \\
{[28]}\end{array}$ & $\begin{array}{l}\text { Urban Tanzania } \\
\text { Health facilities }\end{array}$ & $\begin{array}{l}\text { Naturalistic observation } \\
2014\end{array}$ & $\begin{array}{l}\mathrm{N}=14 \\
\text { Midwives }\end{array}$ & $\begin{array}{l}\text { All midwives showed both } \\
\text { RMC and D\&A instances } \\
\text { Lack of professional } \\
\text { accountability in midwifery }\end{array}$ \\
\hline Citation & Region \& Location & Methodology \& Year & Sample characteristics & Researcher observations \\
\hline $\begin{array}{l}\text { Quality of care } \\
\text { during childbirth in } \\
\text { Tanzania: } \\
\text { identification of } \\
\text { areas that need } \\
\text { improvement } \\
\text { [23] }\end{array}$ & $\begin{array}{l}\text { Lake Zone } \\
\text { Rural district hospital } \\
\text { Rural governmental } \\
\text { health center }\end{array}$ & $\begin{array}{l}\text { Participant Observation } \\
2014-2016\end{array}$ & 1300 hours of observation & $\begin{array}{l}\text { Women's movement } \\
\text { between rooms during birth } \\
\text { Health provider's } \\
\text { assumptions and hope } \\
\text { for a "normal" birth } \\
\text { Fear of poor fetal and } \\
\text { maternal outcomes results } \\
\text { in active management of } \\
\text { labour }\end{array}$ \\
\hline & \multicolumn{4}{|c|}{$\begin{array}{l}\text { Intervention and diagnostic tools are not used as intended. For example, the partograph is more of a documentation } \\
\text { tool than a diagnostic one. Encouragement of use is needed urgently } \\
\text { Culture of "blame and shame" pushes providers into active management without even reasons. Needs to be } \\
\text { reemphasized that maternal and fetal health outcomes are a systemic change and not just individual shortcomings }\end{array}$} \\
\hline
\end{tabular}




\section{Continued}

\begin{tabular}{|c|c|c|c|}
\hline Citation & Region \& Location & Methodology \& Year & Sample characteristics \\
\hline & Dodoma region & $\begin{array}{l}\text { In-depth interviews } \\
2013\end{array}$ & $\begin{array}{l}\mathrm{N}=16 \\
\text { Trained TBA }(\mathrm{n}=3) \\
\text { Untrained TBA }(\mathrm{n}=8) \\
\text { Multiparous women attended to by } \\
\text { untrained TBA }(\mathrm{n}=5)\end{array}$ \\
\hline & Provider self-report & Provider explanations & Recommendations \\
\hline $\begin{array}{l}\text { "We have been } \\
\text { working overnight } \\
\text { without sleeping" } \\
\text { traditional birthing } \\
\text { attendants' practices } \\
\text { and perceptions of } \\
\text { postpartum care } \\
\text { services in rural } \\
\text { Tanzania [30] }\end{array}$ & $\begin{array}{l}\text { Engaging in caring } \\
\text { rituals including } \\
\text { sponging, cooking } \\
\text { special foods such } \\
\text { soups, porridge; } \\
\text { Detected and handled } \\
\text { complications that } \\
\text { might arise post-birth } \\
\text { and used traditional } \\
\text { methods; } \\
\text { Referring only when } \\
\text { complications arise } \\
\text { which cannot be } \\
\text { handled (untrained } \\
\text { TBA) vs. regularly } \\
\text { referring to health } \\
\text { facilities (trained TBA); } \\
\text { Weak connections } \\
\text { between formal health } \\
\text { facilities and TBAs. }\end{array}$ & $\begin{array}{l}\text { Distance to women is a } \\
\text { big factor in postpartum } \\
\text { care }\end{array}$ & $\begin{array}{l}\text { Strengthening the connections between health facilities and } \\
\text { TBA. } \\
\text { Training more and more TBAs increases education and } \\
\text { awareness of the postpartum issues. } \\
\text { Increased training and referral mechanisms can increase } \\
\text { quality } \\
\text { Bridge the gap between facility and home births via a skilled } \\
\text { provider in terms of the trained TBA }\end{array}$ \\
\hline
\end{tabular}

\section{Citation}

Region \& Location

Methodology \& Year

Sample characteristics

Researcher observations

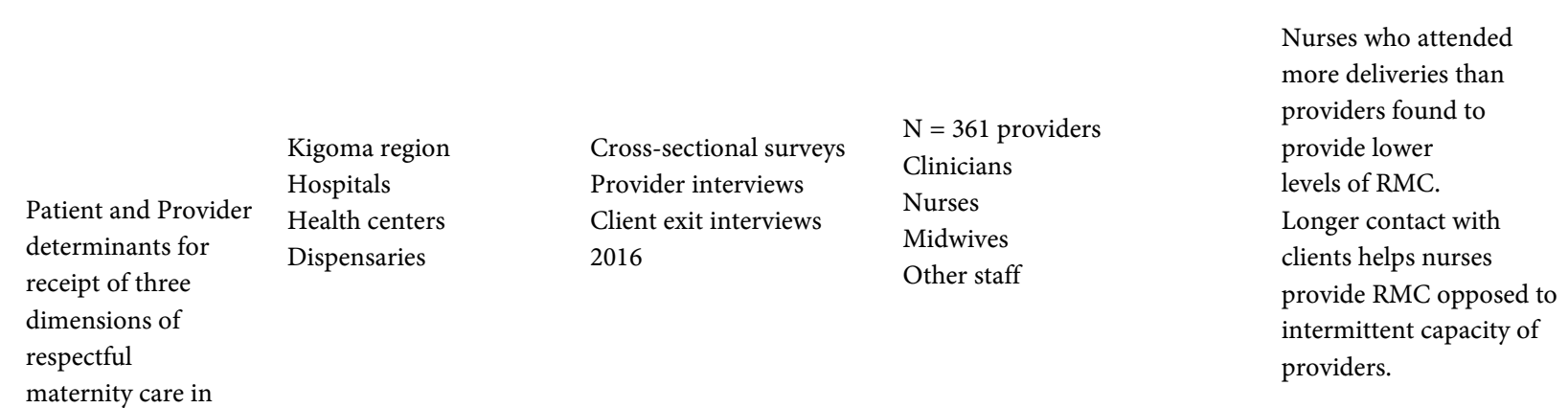

\section{Provider self-report}

Perception of pay equity fosters friendly and empathetic RMC

\section{Recommendations}

High workload, low motivation, pay inequity negatively affects provider's ability to provide RMC

\begin{tabular}{lcc}
\hline Citation & Region \& Location & Methodology \& Year \\
\hline DOI: $10.4236 /$ ojog.2021.119118 & 1263 & Open Journal of Obstetrics and Gynecology
\end{tabular}




\section{Continued}

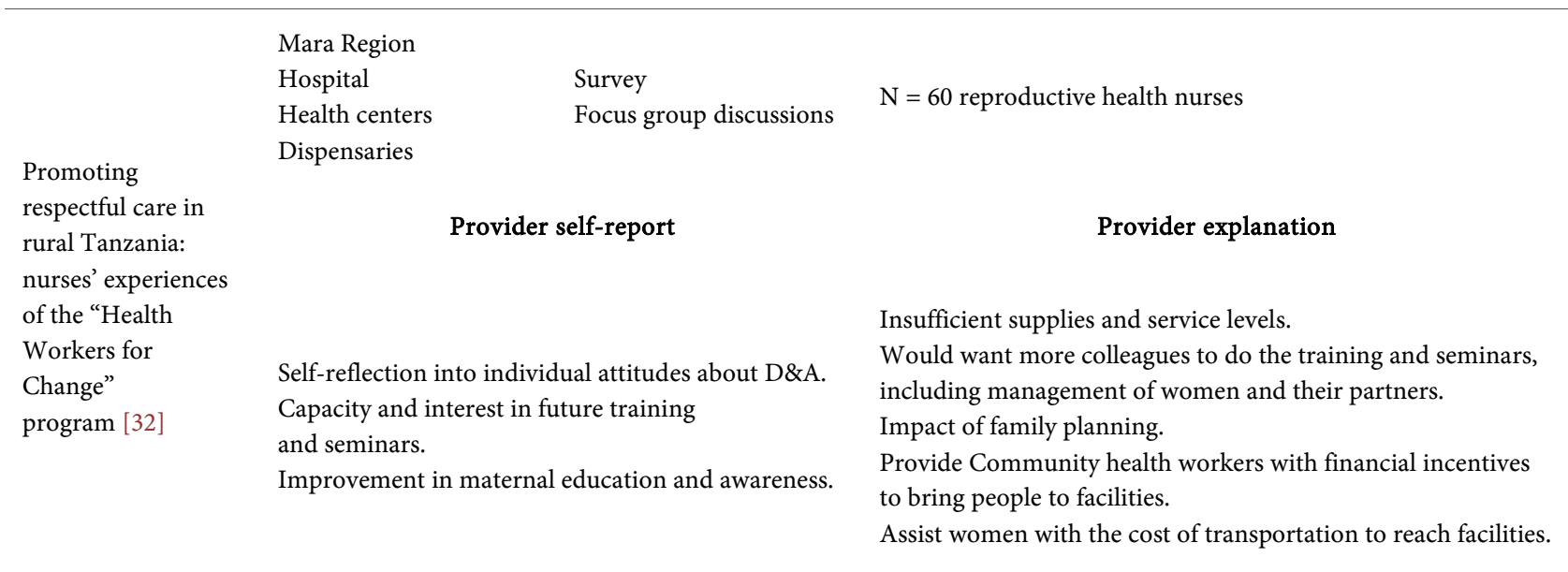

Table 6. The staha intervention.

\begin{tabular}{|c|c|c|c|}
\hline Citation & Region \& Location & Methodology \& Year & Intervention Design \\
\hline $\begin{array}{l}\text { Community and health } \\
\text { system intervention to } \\
\text { reduce disrespect and abuse } \\
\text { during childbirth in Tanga } \\
\text { region: A comparative } \\
\text { before-and-after study [44] }\end{array}$ & $\begin{array}{l}\text { D\&A events reported } \\
\text { Women in intervention } \\
\text { facility were less likely to } \\
\text { report neglect (OR: } 0.36,95 \% \\
\text { CI: } 0.19-0.71 \text { ). } \\
\text { Less likely to report physical } \\
\text { abuse (OR: } 0.22,95 \% \\
\text { CI: } 0.05 \text { - } 0.97) \text {. } \\
\text { Increased likelihood of rating } \\
\text { the care received as excellent } \\
\text { or very good. } \\
\text { and rating the respect } \\
\text { providers showed them as } \\
\text { excellent or very good. }\end{array}$ & \multicolumn{2}{|c|}{$\begin{array}{l}3.39 \% \text { decrease in percent of all women who experienced D\&A } \\
\text { between control and intervention health facility. } \\
\text { Staha Intervention was linked with } 66 \% \text { reduced odds of a woman } \\
\text { experiencing D\&A during childbirth. }\end{array}$} \\
\hline
\end{tabular}

\subsection{The Patient Perspective}

Most studies on obstetric D\&A in Tanzania focus on the patient perspective and experience. As Table 1 shows, almost all forms of Browser and Hill's D\&A categorization have been reported to various degrees. Most frequently reported events include non-dignified care, non-confidential care, and verbal abuse [33] 
[34] [35]. Another category reported is the detention of women in facilities for financial reasons as well as demands for unofficial payments [37]. Across qualitative interviews, women recalled events which constitute D\&A that do not fall under any predetermined category. Additionally, due to the nature of D\&A, many reports overlap across categories, making clear distinctions difficult. It is important to take these factors into account when interpreting D\&A prevalence.

In several studies, women voiced the need for a support companion during the labor process [33] [36] [37]. In accordance with birthing traditions, this companion could be the spouse, family members, close friends, and community leaders, or TBAs. However, owing to space constraints this request is not easily fulfilled. Additionally, having non-clinical personnel present in closed quarters could result in privacy violations for laboring women in the ward. Women often perceived the labor and delivery wards to be unwelcoming and disconcerting, exacerbating their feeling of discomfort and disrespect [43]. This highlights the need for a systemic intervention to successfully address D\&A integral to the delivery process.

Disrespect and abuse during childbirth are a violation of a woman's fundamental human rights. D\&A at the facility level can reflect the structural violence against women in society at large [23]. Systematic gender inequalities reinforce the vulnerability of women to abuse when they encounter a situation where there is a power differential. One way this dynamic can play out is in the provider-patient relationship. As the selected literature illustrates, many women don't feel comfortable in their relationship with their providers. They may hesitate to ask questions or raise concerns out of fear of repercussions-a hesitancy that is particularly concerning during the health care consent process. For example, there are numerous reports of women not being covered during vaginal examinations, and not being asked for consent before episiotomies and other medical procedures [33] [35] [36] [37]. The feeling of disrespect and abuse such conduct engenders further widens the power gap between providers and patients, which in turn can discourage women from seeking facility-based care for future pregnancies [10].

The studies examining D\&A from the patient's perspective most often utilize direct observation of the patient-provider interaction and/or qualitative methods such as in-depth interviews and focus group discussions with participants [34] [35] [43]. Direct observation methodology requires the researcher to observe from a distance without any participation in the process. This brings up an important question about inadvertent researcher bias based on researcher interpretation. Another potential issue is the observer's familiarity with the norms of care prevalent in the specific region of Tanzania, which is reflected in the discrepancies between reported events versus observed events [34] [35] [43]. Conducts that appear disrespectful and abusive to an observer may be experienced by the patients as normal behavior. Therefore, although a difficult task to accomplish, it is necessary to find a way to converge patients' views of D\&A and 
researchers' observations.

Qualitative methods such as in-depth interviews and focus group discussions are extremely useful to glean information on a more nuanced understanding of D\&A. However, the timing of the interview or discussion post-birth can yield very different results. In some studies, participants were interviewed postpartum but before discharge from the facility, and in others, community follow-up interviews were also conducted four to six weeks postpartum. Across the studies, community follow-up interviews yielded higher reports of D\&A compared to those conducted before discharge [34] [35] [43]. A plausible explanation for this discrepancy is that D\&A incidences may not be at the forefront of their mind in the immediate aftermath of giving birth, but upon recounting their birth story several weeks later, women more readily recall disrespectful and abusive events and circumstances [45]. These occurrences may not have been at the forefront of their mind in the immediate aftermath of giving birth. Furthermore, the location of the interview may lead to underreporting. Women may not report D\&A events while at the facility out of fear of repercussions from the providers. Thus, it becomes extremely important to address the impact of bias on D\&A prevalence.

\subsection{The Provider Perspective}

Although provider perspectives are essential to understanding the root causes of D\&A, relatively few studies have prioritized them. Numerous factors-both systemic and individual-influence provider's perception of their conduct and that of their colleagues. Addressing D\&A in childbirth requires a better understanding of the complex, nuanced forces driving provider's behaviors.

Systematic factors include infrastructure and resource limitations that are often beyond the control of providers. As mentioned above, space restrictions can lead to violation of privacy, cultural norms, and traditions. These violations can lead to feelings of disrespect among patients, and providers barely have any ability to mitigate the circumstances [27] [28] [29]. Shortage in staffing can overwhelm workers and create a stressful working environment, leading to D\&A incidents. Job satisfaction, pay equity, and working hours directly impact the care provided. Excessively long and grueling working hours can affect provider demeanor and adaptability to emergencies. Additionally, staff shortages limit the time providers can spend with each patient. This negatively impacts rapport building, which may increase discomfort and dissatisfaction amongst patients [31].

Apart from systemic factors, individual factors such as personal prejudices, sexism, and paternalism also determine provider's perceptions of D\&A [46]. However, it is important to emphasize that for the most part, providers do not intend to act disrespectfully or maliciously. Often their conduct is a reaction to external circumstances and pressures beyond their control.

The chosen literature offers several recommendations to address the root 
causes of D\&A. As numerous providers acknowledged, there is a need for uniform supervision across the board [27] [28] [30] [32]. This includes engagement in training as well as encouraging the use of monitoring tools such as partographs. The desire to provide efficient, effective and respectful maternity care is apparent in the results of the Staha intervention summarized in Table 5. The intervention activates a maternity care charter rooted in the communal ethos of the region and health systems to foster respectful maternity care. Input provided by community stakeholders and health experts ensures a holistic, feasible, and comprehensive view of D\&A at large [44]. However, with only two facilities in the pilot study, significant regional expansion is required to fully determine the generalizability and efficacy of the intervention. Additionally, further research is required to determine the financial sustainability of such interventions and the feasibility to integrate them into the Tanzanian healthcare system.

\section{Future Recommendations}

Analysis of the chosen literature revealed three key takeaway points about disrespect and abuse in Tanzania. First, it is important to restructure the public perception of healthcare providers. Changes at the organizational level are required to ensure providers' wellbeing and health. Grueling shifts, job inequity, and an inherent fear of being blamed and subjected to violence considerably impact the quality of care. There are numerous reports of workplace violence against health workers by relatives of patients in the African continent [47]. The literature on workplace violence against healthcare workers is limited. Hence, future research should address the need to encourage respectful care by both patient and provider alike.

Second, the chosen literature indicates a wide power gap in the relationship between patient and provider. The high provider to patient ratio significantly detracts the quality of care. Thus, government and healthcare policies must be restructured to integrate TBAs into the health sector formally. A standardized training procedure and incentivization of dedicated community members will expand the availability of skilled medical coverage in the country. This would ensure accredited maternal care is available to more women, particularly those living in remote areas or who are unable to fund facility births. Further, the familiarity of the TBA with their community will foster adherence to and respect of local birthing traditions and norms. Third, it is important to standardize measurement and research techniques for D\&A in Tanzania. There is a paucity of a consensus on units of measurement and subsequent analysis. This becomes particularly important during observational studies. A standardized measurement technique would eliminate some of the bias to which this form of research is susceptible.

\section{Conclusion}

In recent years, Tanzania has made significant strides towards improving ma- 
ternal and fetal outcomes. Extensive programming and interventions have been introduced to reduce the MMR and foster maternal wellbeing. There has been a push for facility-based deliveries under skilled providers to decrease maternal mortality. However, disrespect and abuse during labor and delivery hinder further progress. D\&A in Tanzania is a complex issue; addressing it requires a comprehensive and multifaceted approach that integrates patient and provider perspectives.

\section{Conflicts of Interest}

The authors declare no conflicts of interest regarding the publication of this paper.

\section{References}

[1] Ronsmans, C. and Graham, W.J., on Behalf of the Lancet Maternal Survival Series Steering Group (2006) Maternal Mortality: Who, When, Where, and Why. Lancet, 368, 1189-1200. https://doi.org/10.1016/S0140-6736(06)69380-X

[2] World Health Organization (n.d.) Tanzania. https://www.who.int/pmnch/activities/countries/tanzania/en/index1.html

[3] Umeora, O.U.J. and Egwuatu, V.E. (2010) The Role of Unorthodox and Traditional Birth Care in Maternal Mortality. Tropical Doctor, 40, 13-17. https://doi.org/10.1258\%2Ftd.2009.080207

[4] Moshi, F.V., Lymo, G., Gibore, N.S. and Kibusi, S.M. (2020) Prevalence and Factors Associated with Home Childbirth with Unskilled Birth Assistance in Dodoma-Tanzania: A Cross Sectional Study. East African Health Research Journal, 4, 92-100. https://doi.org/10.24248/eahrj.v4i1.626

[5] Schroll, A.-M., Kjærgaard, H. and Midtgaard, J. (2013) Encountering Abuse in Health Care; Lifetime Experiences in Postnatal Women-A Qualitative Study. BMC Pregnancy and Childbirth, 13, Article No. 74. https://doi.org/10.1186/1471-2393-13-74 https://bmcpregnancychildbirth.biomedcentral.com/articles/10.1186/1471-2393-1374

[6] United Nations Human Rights (1993) Declaration on the Elimination of Violence against Women.

https://www.ohchr.org/en/professionalinterest/pages/violenceagainstwomen.aspx

[7] Savage, V. and Castro, A. (2017) Measuring Mistreatment of Women during Childbirth: A Review of Terminology and Methodological Approaches. Reproductive Health, 14, 1-27. https://doi.org/10.1186/s12978-017-0403-5

[8] United Nations (2000) United Nations Millennium Development Goals. https://www.un.org/millenniumgoals/maternal.shtml

[9] Freedman, L.P., Ramsey, K., Abuya, T., Bellows, B., Ndwiga, C., Warren, C.E., et al. (2014) Defining Disrespect and Abuse of Women in Childbirth: A Research, Policy and Rights Agenda. Bulletin of the World Health Organization, 92, 915-917. https://doi.org/10.2471/BLT.14.137869

[10] Bowser, D. and Hill, K. (2010) Exploring Evidence for Disrespect and Abuse in Facility-Based Childbirth. USAID-TRAction Project, Harvard School of Public Health, Boston, p. 3.

[11] Okafor, I.I., Ugwu, E.O. and Obi, S.N. (2015) Disrespect and Abuse during Facili- 
ty-Based Childbirth in a Low-Income Country. International Journal of Gynecology \& Obstetrics, 128, 110-113. https://doi.org/10.1016/j.ijgo.2014.08.015

[12] Ministry of Health, Community Development, Gender, Elderly and Children (MoHCDGEC) [Tanzania Mainland], Ministry of Health $(\mathrm{MoH})$ [Zanzibar], National Bureau of Statistics (NBS), Office of the Chief Government Statistician (OCGS) and ICF (2016) Tanzania Demographic and Health Survey and Malaria Indicator Survey (TDHS-MIS) 2015-2016. MoHCDGEC, MoH, NBS, OCGS, and ICF, Dar es Salaam, Tanzania, and Rockville, Maryland.

[13] World Bank Data (2019) Population, Total-Tanzania. https://data.worldbank.org/indicator/SP.POP.TOTL?locations=TZ

[14] Discover Africa Safaris (2021) Languages Spoken in Tanzania. https://www.discoverafrica.com/safaris/tanzania/languages-spoken-in-tanzania/

[15] Lawrence, D. (2009) Tanzania and Its People. New Africa Press, 230 p.

[16] Klein, E., Helzner, E., Shayowitz, M., Kohlhoff, S. and Smith-Norowitz, T.A. (2018) Female Genital Mutilation: Health Consequences and Complications-A Short Literature Review. Obstetrics and Gynecology International, 2018, Article ID: 7365715. https://doi.org/10.1155/2018/7365715

[17] World Health Organization (2019) Maternal Mortality. https://www.who.int/news-room/fact-sheets/detail/maternal-mortality

[18] World Bank Data (2019) Lifetime Risk of Maternal Death (\%)_Tanzania. https://data.worldbank.org/indicator/SH.MMR.RISK.ZS?locations=TZ

[19] World Health Organization (2021) Infant Mortality Rate. https://www.who.int/data/gho/indicator-metadata-registry/imr-details/3138

[20] United States Agency for International Development (2017) Tanzania Profile of Preterm and Low Birth Weight Prevention and Care. Every Preemie Scale-USAID.

[21] World Health Organization (2016) WHO Recommendations on Antenatal Care for a Positive Pregnancy Experience. World Health Organization, Geneva. https://www.who.int/publications-detail-redirect/9789241549912

[22] Women's Dignity Project and Engender Health (2006) Risk and Resilience: Obstetric Fistula in Tanzania. Women's Dignity Project and Engender Health, Dar es Salaam.

[23] Solnes Miltenburg, A., Kiritta, R.F., Meguid, T. and Sundby, J. (2018) Quality of Care during Childbirth in Tanzania: Identification of Areas That Need Improvement. Reproductive Health, 15, Article No. 14. https://doi.org/10.1186/s12978-018-0463-1

[24] Moshi, F.V., Kibusi, S.M. and Fabian, F. (2020) Exploring Factors Influencing Pregnant Women's Attitudes, Perceived Subjective Norms and Perceived Behavior Control towards Male Involvement in Maternal Services Utilization: A Baseline Finding from a Community Based Interventional Study from Rukwa, Rural Tanzania. BMC Pregnancy Childbirth, 20, Article No. 634. https://doi.org/10.1186/s12884-020-03321-z

[25] Ohnishi, M., Oishi, K. and Leshabari, S. (2015) Customs and Practices during Pregnancy, Childbirth, and the Postpartum Period in the Kilimanjaro Area, Tanzania. Health Science Research, 27, 85-90.

[26] Moshi, F. and Nyamhanga, T. (2017) Understanding the Preference for Homebirth: An Exploration of Key Barriers to Facility Delivery in Rural Tanzania. Reproductive Health, 14, Article No. 132. https://doi.org/10.1186/s12978-017-0397-z

[27] Shimoda, K., Leshabari, S. and Horiuchi, S. (2020) Self-Reported Disrespect and Abuse by Nurses and Midwives during Childbirth in Tanzania: A Cross-Sectional 
Study. BMC Pregnancy Childbirth, 20, Article No. 584. https://doi.org/10.1186/s12884-020-03256-5

[28] Shimoda, K., Horiuchi, S., Leshabari, S. and Shimpuku, Y. (2018) Midwives' Respect and Disrespect of Women during Facility-Based Childbirth in Urban Tanzania: A Qualitative Study. Reproductive Health, 15, Article No. 8.

https://doi.org/10.1186/s12978-017-0447-6

[29] Mselle, L.T., Kohi, T.W. and Dol, J. (2018) Barriers and Facilitators to Humanizing Birth Care in Tanzania: Findings from Semi-Structured Interviews with Midwives and Obstetricians. Reproductive Health, 15, Article No. 137.

https://doi.org/10.1186/s12978-018-0583-7

[30] Mahiti, G.R., Kiwara, A.D., Mbekenga, C.K., Hurtig, A.-K. and Goicolea, I. (2015) "We Have Been Working Overnight without Sleeping": Traditional Birth Attendants' Practices and Perceptions of Post-Partum Care Services in Rural Tanzania. BMC Pregnancy Childbirth, 15, Article No. 8. https://doi.org/10.1186/s12884-015-0445-Z

[31] Dynes, M.M., Twentyman, E., Kelly, L., Maro, G., Msuya, A.A., Dominico, S., et al. (2018) Patient and Provider Determinants for Receipt of Three Dimensions of Respectful Maternity Care in Kigoma Region, Tanzania-April-July, 2016. Reproductive Health, 15, Article No. 41. https://doi.org/10.1186/s12978-018-0486-7

[32] Webber, G., Chirangi, B. and Magatti, N. (2018) Promoting Respectful Maternity Care in Rural Tanzania: Nurses' Experiences of the "Health Workers for Change" Program. BMC Health Services Research, 18, Article No. 658. https://doi.org/10.1186/s12913-018-3463-5

[33] Bishanga, D.R., Massenga, J., Mwanamsangu, A.H., Kim, Y.-M., George, J., Kapologwe, N.A., et al. (2019) Women's Experience of Facility-Based Childbirth Care and Receipt of an Early Postnatal Check for Herself and Her Newborn in Northwestern Tanzania. International Journal of Environmental Research and Public Health, 16, Article No. 481. https://doi.org/10.3390/ijerph16030481

[34] Kruk, M.E., Kujawski, S., Mbaruku, G., Ramsey, K., Moyo, W. and Freedman, L.P. (2018) Disrespectful and Abusive Treatment during Facility Delivery in Tanzania: A Facility and Community Survey. Health Policy and Planning, 33, e26-e33. https://doi.org/10.1093/heapol/czu079

[35] Sando, D., Ratcliffe, H., McDonald, K., Spiegelman, D., Lyatuu, G., Mwanyika-Sando, M., et al. (2016) The Prevalence of Disrespect and Abuse during Facility-Based Childbirth in Urban Tanzania. BMC Pregnancy Childbirth, 16, Article No. 236. https://doi.org/10.1186/s12884-016-1019-4

[36] Mselle, L.T., Kohi, T.W. and Dol, J. (2019) Humanizing Birth in Tanzania: A Qualitative Study on the (Mis) Treatment of Women during Childbirth from the Perspective of Mothers and Fathers. BMC Pregnancy Childbirth, 19, Article No. 231. https://doi.org/10.1186/s12884-019-2385-5

[37] McMahon, S.A., George, A.S., Chebet, J.J., Mosha, I.H., Mpembeni, R.N. and Winch, P.J. (2014) Experiences of and Responses to Disrespectful Maternity Care and Abuse during Childbirth: A Qualitative Study with Women and Men in Morogoro Region, Tanzania. BMC Pregnancy Childbirth, 14, Article No. 268. https://doi.org/10.1186/1471-2393-14-268

[38] Solnes Miltenburg, A., van Pelt, S., Meguid, T. and Sundby, J. (2018) Disrespect and Abuse in Maternity Care: Individual Consequences of Structural Violence. Reproductive Health Matters, 26, 88-106. https://doi.org/10.1080/09688080.2018.1502023

[39] Research Methods in Psychology (2021) 6.5 Observational Research. 
https://opentext.wsu.edu/carriecuttler/chapter/observational-research/

[40] Jamshed, S. (2014) Qualitative Research Method-Interviewing and Observation. Journal of Basic and Clinical Pharmacy, 5, 87-88.

[41] Shorten, A. and Smith, J. (2017) Mixed Methods Research: Expanding the Evidence Base. Evidence-Based Nursing, 20, 74-75. https://doi.org/10.1136/eb-2017-102699

[42] Coffta, M. (2020) LibGuides: Literature Review: What Is a Literature Review? https://guides.library.bloomu.edu/c.php?g=318537\&p=2127820

[43] Freedman, L.P., Kujawski, S.A., Mbuyita, S., Kuwawenaruwa, A., Kruk, M.E., Ramsey, K., et al. (2018) Eye of the Beholder? Observation versus Self-Report in the Measurement of Disrespect and Abuse during Facility-Based Childbirth. Reproductive Health Matters, 26, 107-122. https://doi.org/10.1080/09688080.2018.1502024

[44] Kujawski, S.A., Freedman, L.P., Ramsey, K., Mbaruku, G., Mbuyita, S., Moyo, W., et al. (2017) Community and Health System Intervention to Reduce Disrespect and Abuse during Childbirth in Tanga Region, Tanzania: A Comparative Before-andAfter Study. PLoS Medicine, 14, Article ID: e1002341.

https://doi.org/10.1371/journal.pmed.1002341

[45] Sando, D., Abuya, T., Asefa, A., Banks, K.P., Freedman, L.P., Kujawski, S., et al. (2017) Methods Used in Prevalence Studies of Disrespect and Abuse during Facility Based Childbirth: Lessons Learned. Reproductive Health, 14, Article No. 127. https://doi.org/10.1186/s12978-017-0389-Z

[46] Perrotte, V., Chaudhary, A. and Goodman, A. (2020) "At Least Your Baby Is Healthy" Obstetric Violence or Disrespect and Abuse in Childbirth Occurrence Worldwide: A Literature Review. Open Journal of Obstetrics and Gynecology, 10, 1544-1562. https://doi.org/10.4236/ojog.2020.10110139

[47] Njaka, S., Edeogu, O.C., Oko, C.C., Goni, M.D. and Nkadi, N. (2020) Work Place Violence (WPV) against Healthcare Workers in Africa: A Systematic Review. $\mathrm{He}-$ liyon, 6, Article ID: e04800. https://doi.org/10.1016/j.heliyon.2020.e04800 
Abbreviations

\begin{tabular}{ll}
\hline Abbreviation & Description \\
\hline ANC & Antenatal care \\
D\&A & Disrespect and abuse \\
DHS & Demographic and Health Survey \\
EmOC & Emergency Obstetric Care \\
FGC & Female Genital Circumcision \\
MMR & Maternal Mortality Ratio \\
TBA & Traditional birthing assistant \\
USAID & United States Agency for International Development \\
WHO & World Health Organization \\
\hline
\end{tabular}

